\title{
ERRATUM
}

\section{Atlas of Hematologic Neoplasms}

Tsieh Sun

\author{
Director of Hematopathology and Flow Cytometry \\ Pathology and Laboratory Medicine Service \\ Veterans Affairs Medical Center \\ Eastern Colorado Health Care System \\ Professor of Pathology Department of Pathology \\ University of Colorado School of Medicine \\ Denver, Colorado 80220 \\ USA \\ tsieh.jack.sun@va.gov
}

(c) Springer Science+Business Media, LLC 2009

DOI 10.1007/978-0-387-89848-3

In the print and online version of the table of contents, Case 79 should be Merkel Cell Carcinoma, not Hematogones in postchemotherapy bone marrow.

The online version of the table of contents can be found at http://dx.doi.org/10.1007/978-0-387-89848-3 